В. В. Безпалов, Д. В. Федюнин, С. А. Автономова. Методы и инструменты разработки фирменного стиля компании в условиях высококонкурентных рынков

Научная статья

УДК 659.127 .3

DOI 10.18101/2304-4446-2021-1-21-34

\title{
МЕТОДЫ И ИНСТРУМЕНТЫ РАЗРАБОТКИ ФИРМЕННОГО СТИЛЯ КОМПАНИИ В УСЛОВИЯХ ВЫСОКОКОНКУРЕНТНЫХ РЫНКОВ
}

(C) Безпалов Валерий Васильевич

доктор экономических наук, доцент valeri61@yndex.ru

(C) Федюнин Дмитрий Валерьевич доктор экономических наук, доцент fedyuninDV@rea.ru

(C) Автономова Светлана Алексеевна кандидат социологических наук, доцент avtonomova.SA@rea.ru

Российский экономический университет им. Г. В. Плеханова Россия, 117997, г. Москва, Стремянный переулок, 36

Аннотация. После введения Россией антисанкций по отношению к некоторой зарубежной продукции актуальной становится пропаганда темы импортозамещения в целях реализации мероприятий по достижению экономического роста страны. В статье рассмотрены мероприятия по реализации задачи современного маркетолога, которая заключается в создании конкурентоспособного отечественного бренда и разработке нового имени. Санкции, в условиях которых в настоящее время пребывает Россия в целом и российские компании в частности, могут послужить основой для повышения уровня отечественного производства и привлечения «своего» потребителя к отечественной продукции. Для этого необходимо не только сформировать образ «отечественный гарант качества», но и сделать этот товар наиболее узнаваемым и популярным.

Ключевые слова: фирменный стиль; отечественный бренд; санкции; высококонкурентные рынки; товарный знак; цветовое и графическое оформление фирменной документации организации.

\section{Для цитирования}

Безпалов В. В., Федюнин Д. В., Автономова С. А. Методы и инструменты разработки фирменного стиля компании в условиях высококонкурентных рынков // Вестник Бурятского государственного университета. Экономика и менеджмент. 2021. № 1. C. 21-34.

Фирменный стиль выступает одним из ключевых инструментов создания бренда и одновременно является элементом брендинга. Анализируя теоретические и методологические аспекты создания фирменного стиля компании, необходимо отметить, что в современных литературных источниках можно встретить множество подходов к определению фирменного или корпоративного стиля. 
Современные компании для упрощения фирменный стиль рассматривают в узком понимании, а именно подразумевают по ним комплекс, элементами которого являются товарный знак, цветовое и графическое оформление фирменной документации организации [4]. В широком понимании фирменный стиль рассматривается в качестве единого стандарта компании по оформлению, использованию цветовых гамм и образов, а также единое композиционное оформление фирменной одежды сотрудников, внутренней документации, рекламных носителей и т. д. Таким образом, на основании вышесказанного можно заключить, что фирменный стиль - это целый комплекс приемов, методов и инструментов, целью применения которых является обеспечение единого образа всех отдельно взятых элементов компании и проводимых ею мероприятий, что способствует улучшению потребительского восприятия и запоминаемости товаров (услуг) фирмы, вызывает ассоциативный ряд, связанный со всей ее деятельностью, а также позволяют быть конкурентоспособным на рынке [1].

После введения Россией антисанкций по отношению к некоторой зарубежной продукции актуальной становится пропаганда темы импортозамещения в целях реализации мероприятий по достижению экономического роста страны. Специалистам в области маркетинга приходится адаптировать стратегию в соответствии с текущими условиями и осуществлять разработку «лица российского бренда».

В сложившейся ситуации важным и актуальным является изменение мышления и ментальности потребителей посредством убеждения, что отечественные продукты и услуги качественно не уступают, а иногда даже оказываются лучше зарубежных. Задача современного маркетолога заключается в создании конкурентоспособного отечественного бренда и разработке нового - мощного, узнаваемого, громкого и жизнеутверждающего имени.

В сложившейся непростой социально-экономической ситуации в стране деятельность PR-специалиста призвана оказать существенную помощь бизнесу, прежде всего в реализации маркетинговых стратегий в условиях ограниченного бюджета [7]. В данном случае актуальным становится использование бесплатных инструментов для продвижения товаров или услуг.

В санкционных условиях разработка фирменного стиля будет происходить с учетом следующих факторов, которые оказывают непосредственное влияние на возникновение проблем и возможностей [9]:

1. Уход крупных зарубежных конкурентов, вызванный затруднениями в осуществлении их деятельности на российской территории ввиду применения антироссийских санкций:

- проблема - обострение внутренней конкуренции в стране (отечественные компании предпринимают существенные усилия по привлечению клиентов, которые вынуждены были отказаться от зарубежных товаров и услуг);

- возможность - снижения влияния на потребителей крупных известных брендов, потенциал создания отечественных влиятельных брендов.

2. Снижение влияния известных брендов на российских потребителей, вызванное уходом крупных зарубежных конкурентов:

- проблема - приверженность потребителей зарубежным брендам, трудности с переключением внимания российский потребителей к отечественным брендам; 
В. В. Безпалов, Д. В. Федюнин, С. А. Автономова. Методы и инструменты разработки фирменного стиля компании в условиях высококонкурентных рынков

- возможность - изучение потребителей и разработка уникального отечественного бренда, отвечающего запросам и потребностям российских покупателей.

3. Уменьшение исследований зарубежными компаниями российских потребителей из-за ухода крупных зарубежных конкурентов:

- проблема - недостаточный отечественный опыт в изучении потребителей, отсутствие отечественного инструментария и разработок в способах исследования потребителей;

- возможность - активное привлечение отечественных специалистов к исследованию потребителей и накопление опыта в разработках отечественного инструментария по изучению потребителей с целью создания привлекательного бренда.

Таким образом, можно заключить, что санкции, в условиях которых в настоящее время пребывает Россия в целом и российские компании в частности, могут послужить основой для повышения уровня отечественного производства и привлечения «своего» потребителя к отечественной продукции. Для этого необходимо не только сформировать образ «отечественный гарант качества», но и сделать этот товар наиболее узнаваемым и популярным.

Основными составляющими фирменного стиля, например, для медицинских учреждений является [11]:

1. Имиджевая составляющая. Привлекательность образа медицинской организации влияет на его узнаваемость и на репутацию. Согласно психологии потребителя, человек предпочтет обратиться за услугами к известному бренду, оказывая ему доверие больше, чем малознакомым названиям. При этом высокие цены не остановят клиента.

2. Идентифицирующая составляющая. Фирменный стиль медицинского учреждения сразу покажет человеку, какие именно услуги оказывает данная организация.

3. Дифференцирующая составляющая. Благодаря фирменному стилю медицинское учреждение может выделиться среди подобных компаний, которые занимаются той же деятельностью. Он предоставит информацию, которая поможет потребителю определиться с тем, что ему необходимо [2].

В настоящее время реклама имеется повсюду, где возможно и в огромных количествах. В связи с этим многие потребители часто не акцентируют на ней свое внимание. Однако если человек уже знаком с фирменным стилем медицинского учреждения, то существуют высокие шансы на то, что он заметит в обширном информационном потоке определенный логотип.

Самым используемым в фирменном стиле медицинских учреждений является синий цвет и его сопутствующие оттенки. Он выделяется как наиболее «спокойный» в психоэмоциональном восприятии. Синий цвет не способствует усилению тревоги до этого взволнованного пациента, который обращается в клинику в поисках помощи. Однако это вовсе не означает, что цветовое решение фирменного стиля в медицинской организации ограничивается этим цветом [13].

С областью медицины имеет связь другой графический образ - красный крест. А также можно выделить второстепенные узнаваемые элементы: образ 
змеи, которая обвивает чашу, или зеленый цвет формы медицинских работников. Например, такая униформа присуще службе скорой помощи и хирургам.

При выборе цветовой гаммы для оформления экстерьера и интерьера медицинского учреждения необходимо использовать советы цветопсихологов, которые рекомендуют избегать агрессивных или мрачных цветов. В сознании людей ассоциируется белый цвет с чистотой, здоровьем и медициной, в связи с этим можно применять его, сочетая с другими оттенками в качестве цветового решения помещений [3].

В цифровую эпоху, когда ценность коммуникаций с потребителем становится важной необходимостью, фокус внимания каждого человека становится все короче, а выделиться из ряда аналогичных компаний все сложнее, фирменный стиль становится мощнейшим ассоциативным индикатором и фактором повышения узнаваемости среди целевых аудиторий. Для того чтобы компанию можно было идентифицировать в сознании потребителя, релевантным становится создание целостного образа.

Развитие мирового рынка медицинских услуг в настоящее время осуществляется в условиях высокой конкуренции, глобализации и совершенствования цифровых технологий [5]. Факторами конкурентоспособности поставщиков медицинских услуг на мировом рынке являются:

- доступ к инвестициям в условиях развитого частного сектора здравоохранения;

- предоставление инновационных и уникальных медицинских услуг;

- квалифицированный медицинский персонал;

- конкурентоспособные цены при наличии сертификата международной аккредитации, наличие государственной поддержки экспорта медицинских услуг.

Ключевыми тенденциями развития мирового рынка медицинских услуг являются активное включение медицинской услуги в международный обмен; формирование международной медицинской специализации стран; расширение применения телемедицинских технологий; увеличение расходов на медицинские услуги в мире.

В настоящее время мировой рынок медицинских услуг оценивается в более чем 7 триллионов долларов. Основные страны по объему оказываемых медицинских услуг - США, Китай, Германия, Бразилия, Япония, Великобритания, Испания, Россия, Франция, Австралия, Италия, Индия и некоторые другие.

По прогнозам, ожидаемое увеличение совокупного годового темпа роста расходов на здравоохранение во всем мире на 5\% в 2020-2023 гг. откроет перед отраслью многочисленные возможности. В условиях неопределенности заинтересованные стороны могут воспользоваться преимуществами сложившейся ситуации, если при разработке стратегии на 2020 и последующие годы будут учитывать исторические и текущие факторы перемен. Среди таких факторов увеличение численности и старение населения, распространение хронических заболеваний, инвестиции в инфраструктуру, технологические достижения, развитие моделей здравоохранения, рост затрат на оплату труда в условиях нехватки квалифицированных кадров, а также расширение систем здравоохранения на развивающихся рынках. 
В. В. Безпалов, Д. В. Федюнин, С. А. Автономова. Методы и инструменты разработки фирменного стиля компании в условиях высококонкурентных рынков

Российский рынок медицинских услуг, в том числе и платных, только встает на путь своего активного развития. В настоящее время осуществляется внедрение технологий, которые используются зарубежными странами уже несколько десятков лет. В связи с этим особую важность и актуальность приобретают инструменты привлечения клиентов, в том числе в рамках развития международного туризма, за счет создания качественного и узнаваемого отечественного бренда.

Если в практику большого количества российских компаний это стало приходить сравнительно недавно, то компании, играющие на мировом рынке, давно приняли тот факт, что, не имея тщательно продуманного и спроектированного на профессиональном уровне фирменного стиля, достигать поставленных целей и удержаться на плаву невозможно [8].

В России до недавнего времени сфера медицинских услуг не нуждалась в активном применении маркетинговых технологий. Компаний, которые предоставляли медицинские услуги, было не так много. Клиенты, как правило, были постоянными. Ситуация кардинально изменилась в начале 2010-х. На российском рынке медицинских услуг появилось большое количество компаний, которые опережали по своей оснащенности многие отечественные бюджетные поликлиники.

В научной как отечественной, так и зарубежной литературе нет четко сформулированных принципов и методов разработки фирменного стиля для компаний сферы медицинских услуг.

Первым принципом разработки фирменного стиля является уместность позиционирования [9]. Он подразумевает, что создание фирменного стиля должно происходить с учетом позиций на рынке, которые медицинское учреждение планирует занять. В качестве примера зарубежной медицинской организации можно привести израильскую клинику Hayat Dr. Gassan Mohammed Awad, специализирующуюся на имплантации, косметике и лечении зубов и характеризующуюся полным вниманием к средствам стерилизации и гигиены, а также умением обращаться с пациентами, возможностью подобрать к любому клиенту подход и миссией сделать счастливыми всех, кто обратится в учреждение.

Вторым принципом является отражение ключевых ценностей, которое подразумевает вербальное и невербальное выражение ценностей медицинского учреждения. В качестве примера зарубежного медицинского центра можно привести берлинскую клинику «Шарите», основанную в 1710 г. За более 300 лет существования специалисты клиники накопили большой опыт в лечении острых и хронических заболеваний, а также проведении хирургических операций разного уровня сложности. В переводе с французского «шарите» означает милосердие. Это название как нельзя лучше выражает отношение сотрудников клиники к своим пациентам. Специализациями клиники является: нейрохирургия, онкология, травматология и спортивные травмы.

Третьим принципом является последовательность, которая выражается в последовательном соблюдении всех этапов разработки фирменного стиля, начиная от формирования технического задания и сбора всей необходимой информации и заканчивая подготовкой официального документа компании, регламентирующего использование элементов фирменного стиля.

Четвертым принципом являются единство и акцент. Единство означает гармоничное взаимодействие всех элементов фирменного стиля, а акцент - при- 
влечение внимания потребителя на конкретном элементе фирменного стиля. Единство и акцент следует рассматривать как взаимосвязанные части системы фирменного стиля медицинского центра.

Пятым принципом является ориентация на рост, который подразумевает разработку фирменного стиля на перспективу развития и расширения бизнеса. Примером американского медицинского центра можно назвать Stanford Medical Center Development, который позиционируется как нацеленный на развитие биомедицины, использует инновационные технологии в медицине. Эта направленность находит свое отражение в названии центра (development от англ. «развитие»).

«Европейский медицинский центр» (ЕМС) был основан в 1989 г. при участии французской компании Europ Assistance для оказания медицинской помощи иностранцам, живущим в Москве. Первоначально клиника состояла из нескольких кабинетов, в которых вели прием иностранные специалисты. Начинание имело большой успех, что позволило владельцам расширить практику и пригласить новых врачей. В 2001 г. была открыта многопрофильная клиника в здании старинного особняка в Спиридоньевском переулке, которая совмещала в себе поликлинику с диагностическими отделениями и стационар. Это была первая частная клиника, предложившая пациентам в Москве медицинское обслуживание по западным стандартам и сервис высочайшего уровня.

Достижение принципов разработки фирменного стиля осуществляется путем использования следующих методов [13]:

1. Разработка фирменного стиля на основе анализа конкурентов и аналогов предполагает изучение элементов фирменного стиля российских и зарубежных медицинских центров.

2. Разработка фирменного стиля на основе анализа особенностей предоставляемых услуг означает использование узнаваемой символики здоровья, здравоохранения, заботы и т. д.

3. Разработка фирменного стиля на основе анализа целевой аудиторий подразумевает изучение потребителей с позиции возникновения ассоциативного ряда с деятельностью медицинского центра (путем проведения анкетирования, интервью, исследования обратной связи).

4. Разработка фирменного стиля на основе анализа сегмента рынка предполагает создание элементов фирменного стиля в соответствии с территориальным охватом (европейский центр), направленностью медицинских услуг (ассоциация со стоматологией имеет изображение зуба) и т. д.

Таким образом, проведенный анализ свидетельствует о том, что Россия характеризуется преемственностью опыта зарубежных медицинских центров в разработке фирменных стилей. Иностранные медицинские учреждения создают фирменные стили в соответствии с рассмотренными принципами и методами.

Использование одного или нескольких методов при разработке фирменного стиля будет способствовать достижению целей миссии и стратегий медицинского учреждения.

Комплексное следование выявленным принципам при разработке фирменного стиля медицинского центра позволит создать успешный, клиентоориентированный, единовыдержанный и конкурентоспособный фирменный стиль. 
В. В. Безпалов, Д. В. Федюнин, С. А. Автономова. Методы и инструменты разработки фирменного стиля компании в условиях высококонкурентных рынков

Рассмотренные ранее факторы, сформированные в условиях антироссийских санкций, приводят к возникновению проблем и возможностей развития рынка платных медицинских услуг в России, а именно уход крупных зарубежных конкурентов, снижение влияния известных брендов на российских потребителей и уменьшение исследований зарубежными компаниями российских потребителей.

Однако их следует дополнить факторами, которые выявлены в результате анализа мировой и отечественной практик:

1. Конкурентный фактор находит свое отражение в следующей закономерности: количество организаций на рынке медицинских услуг ежегодно растет. При разработке фирменного стиля медицинского центра важным и актуальным является создание уникального и неповторимого фирменного стиля, который поможет выделиться среди конкурентов.

2. Социально-экономический фактор. Мировые финансовые кризисы и общая неблагоприятная ситуация в стране оказывают непосредственное влияние на благосостояние граждан, что отражается в снижении доходов граждан. В связи с этим разработка фирменного стиля компании должна быть нацелена на привлечение внимания потребителей путем позиционирования организации (например, как «бюджетные», «доступные» медицинские услуги).

3. Культурный фактор характеризуется, во-первых, возрастающей ролью «моды», трендов на ведение здорового образа жизни, во-вторых, западных веяний на поиск «семейного» врача. Элементы фирменного стиля могут пропагандировать ведение здорового образа жизни или символизировать семейную направленность предлагаемых услуг.

4. Психологический фактор выражается в особенности менталитета российского населения, который обусловливается нежеланием, боязнью, недоверием к медицинским услугам. Фирменный стиль призван зарекомендовать профессионализм и квалификацию сотрудников медицинского центра для формирования стойкой привязанности клиентов.

5. Политический фактор - наличие санкционных ограничений и реализация политики импортозамещения. В сложившейся ситуации важным и актуальным является изменение мышления и ментальности потребителей посредством убеждения, что отечественные продукты и услуги качественно не уступают, а иногда даже оказываются лучше зарубежных.

6. Демографический фактор характеризуется убылью населения. Он приводит к снижению количества потенциальных потребителей медицинских услуг и, соответственно, обострению конкурентной борьбы на рынке медицинских услуг.

Таким образом, проведенный анализ российского сегмента медицинских услуг показывает, что тенденции развития рынка обусловливает наличие множества факторов, которые оказывают непосредственное влияние на создание фирменного стиля. Оптимальный образ компании в данном случае можно сформировать благодаря детальному исследованию рыночных тенденций.

Проведенный SWOT-анализ (табл. 1) деятельности медицинского центра «Авиценна» с учетом изменений фирменного стиля свидетельствует о том, что реализация предложенных в работе стратегии и мероприятий программы разработки фирменного стиля позволит существенно сократить слабые стороны организации со стороны внутренней среды и усилить сильные стороны. 
SWOT-анализ медицинского центра «Авиценна»

\begin{tabular}{|c|c|c|}
\hline & Положительные факторы & Негативные факторы \\
\hline & $\begin{array}{l}\text { Сильные стороны } \text { (внутренний } \\
\text { потенциал) (S) }\end{array}$ & $\begin{array}{l}\text { Слабые стороны (внутренние не- } \\
\text { достатки) (W) }\end{array}$ \\
\hline \multirow[t]{2}{*}{$\begin{array}{l}\text { Внутренняя } \\
\text { среда }\end{array}$} & $\begin{array}{l}\text { 1) местонахождение - центр } \\
\text { города; } \\
\text { 2) большой опыт работы в стома- } \\
\text { тологической сфере; } \\
\text { 3) индивидуальный подход (осо- } \\
\text { бые цены, акции и предложения); } \\
\text { 4) появление конкурентоспособ- } \\
\text { ного бренда; } \\
\text { 5) наличие современных каналов } \\
\text { продвижения; } \\
\text { 6) наличие собственного интер- } \\
\text { нет-сайта; } \\
\text { 7) наличие высоко квалифициро- } \\
\text { ванных специалистов и совре- } \\
\text { менного оборудования; } \\
\text { 8) положительная репутация }\end{array}$ & $\begin{array}{l}\text { 1) высокие цены; } \\
\text { 2) отсутствие собственного интер- } \\
\text { нет-сайта; } \\
\text { 3) отсутствие современных кана- } \\
\text { лов продвижения; } \\
\text { 4) отсутствие изучения клиентов; } \\
\text { 5) отсутствие средств на модерни- } \\
\text { зацию оборудования и технологий; } \\
\text { 6) отсутствие средств на расшире- } \\
\text { ние и развитие деятельности }\end{array}$ \\
\hline & Имеющиеся возможности (O) & Имеющиеся угрозы (Т) \\
\hline $\begin{array}{l}\text { Внешняя } \\
\text { среда }\end{array}$ & $\begin{array}{l}\text { 1) рост рынка стоматологических } \\
\text { услуг; } \\
\text { 2) рост квалификации всех со- } \\
\text { трудников, приобретение нового } \\
\text { оборудования и внедрение инно- } \\
\text { ваций в лечение; } \\
\text { 3) развитие медицинского туриз- } \\
\text { ма; } \\
\text { 4) готовность со стороны клиен- } \\
\text { тов к росту платных медицин- } \\
\text { ских услуг; } \\
\text { 5) способность использовать } \\
\text { навыки и технологические ноу- } \\
\text { хау; } \\
\text { 6) появление новых технологий }\end{array}$ & $\begin{array}{l}\text { 1) неблагоприятная экономическая } \\
\text { ситуация в стране; } \\
\text { 2) усиление позиций компаний- } \\
\text { конкурентов, вероятность появле- } \\
\text { ния крупных конкурентов; } \\
\text { 3) низкая платежеспособность } \\
\text { населения, вызванная карантином } \\
\text { в связи с COVID-19; } \\
\text { 4) дорогостоящие законодательные } \\
\text { требования }\end{array}$ \\
\hline
\end{tabular}

Фирменный стиль был разработан единожды и сохраняет свои черты по настоящее время.

Отличительными элементами фирменного стиля можно определить:

- название «Авиценна», вызывающее стойкую ассоциацию со средневековым персидским ученым, философом и врачом;

- знак креста на логотипе, символизирующий медицинскую деятельность;

- вывеска, которая объединяет в себе вышеперечисленные элементы и цветовое решение (зеленый цвет, во-первых, ассоциируется с медицинскими услугами, во-вторых, в психологии является символом богатства, процветания и сохранения имеющихся достижений). 
В. В. Безпалов, Д. В. Федюнин, С. А. Автономова. Методы и инструменты разработки фирменного стиля компании в условиях высококонкурентных рынков

При разработке фирменного стиля были выдержаны отдельные этапы и отдельные элементы. Например, отсутствуют фирменный слоган, фирменный комплект шрифтов, официальные документы, описывающие концепцию и атрибуты фирменного стиля. Из этого можно сделать вывод о том, что к услугам специализированных маркетинговых агентств медицинский центр «Авиценна» не обращался.

В непосредственной близости от медицинского центра осуществляют свою деятельность порядка 20 учреждений, оказывающих подобного рода услуги, что создает крайне острую конкуренцию и формирует потребность в разработке отличительного образа.

Еще одним усугубляющим ситуацию моментом для медицинского центра «Авиценна» на рынке стоматологических услуг является его убыточная деятельность, которая не позволяет центру направлять свободные средства на разработку запоминающегося фирменного стиля.

Таким образом, в рамках общей оценки медицинского центра «Авиценна» в условиях влияния большого количества внешних и внутренних факторов особое внимание необходимо уделить детализации отдельных этапов разработки фирменного стиля для повышения эффективности деятельности центра и установления устойчивой коммуникативной связи с целевой аудиторией.

Для разработки рекомендаций в рамках повышения эффективности создания фирменного стиля для медицинского центра «Авиценна» необходимо выделить преимущества и недостатки существующего опыта формирования образа компании.

К преимуществам существующего фирменного стиля можно отнести:

- созданные логотип, цвет и название, имеющие стойкую ассоциативную связь с медицинской сферой;

- композиционное единство разработанных элементов фирменного стиля.

Недостатками существующего фирменного стиля являются:

- отсутствие отдельных элементов стиля (слогана, комплекта шрифтов и т. д.);

- сайт медицинского учреждения не активизирован;

- отсутствие средств продвижения страницы в Instagram;

- нет стойкой ассоциативности названия и логотипа со стоматологическими услугами;

- нет единой униформы у сотрудников всего медицинского персонала;

- отсутствие бланков, документов, визиток, сувенирной продукции, выдержанных в едином фирменном стиле;

- оформление помещения и форма сотрудников не выдержаны в фирменном цвете.

Можно сделать вывод, что из пяти рекомендуемых для разработки фирменного стиля принципов соблюдены два: последовательность и ориентация на рост (в названии «медицинский центр» прослеживается ориентация на рост учреждения). Следует добавить оставшиеся три принципа, которые позволят улучшить фирменный стиль медицинского центра «Авиценна» (уместность позиционирования, отражение ключевых ценностей, единство и акцент).

Основным методом разработки фирменного стиля медицинского центра «Авиценна» является метод, основанный на анализе особенностей предоставляемых услуг (использование узнаваемой символики здоровья и названия, связанного с широко известной личностью в области медицины). 
Корпоративная социальная ответственность медицинского центра «Авиценна» как одна из важных платформ для устойчивого развития бизнеса: компания отожествляет свои бизнес-цели с общими интересами, учитывает управленческие, социальные и экологические факторы, осуществляют ее устойчивое развитие.

Компания стремится к тому, чтобы в своей практической деятельности внесенный вклад был долговременным и обоснованным для заинтересованных сторон, главными из которых являются партнеры и поставщики, государство, сотрудники, пациенты.

Даже в период коронавирусной инфекции компания старалась сопереживать, заботиться, идти на всевозможные уступки, профессионально максимально эффективно решать проблемы, чтобы пациенты чувствовали себя комфортно и защищенно.

Ключевое направление КСО МЦ «Авиценна» - общение с заинтересованными сторонами путем реализации целевых медицинских программ поддержки партнеров. Сотрудники МЦ «Авиценна» поощряют социально значимые инициативы, направленные на помощь тем, кто в этом нуждается.

Исходя из всего вышеперечисленного, можно составить SMART-цели для помощи в достижении результата компании. Приведенная таблица является конкретным инструментом управления проекта для совместной работы (табл. 2).

Таблица 2

SMART-цели компании «Авиценна»

\begin{tabular}{|c|c|}
\hline Значение & Пояснение \\
\hline $\begin{array}{l}\text { Specific } \\
\text { (конкретный) }\end{array}$ & $\begin{array}{l}\text { Увеличение собственной прибыли и потенциальных потребителей } \\
\text { организации }\end{array}$ \\
\hline $\begin{array}{l}\text { Measurable } \\
\text { (измеримый) }\end{array}$ & $\begin{array}{l}\text { Увеличение собственной прибыли и потенциальных потребителей } \\
\text { организации на 45\% относительно текущего года }\end{array}$ \\
\hline $\begin{array}{l}\text { Attainable } \\
\text { (достижимый) }\end{array}$ & $\begin{array}{l}\text { Увеличение собственной прибыли и потенциальных потребителей } \\
\text { организации на } 45 \% \text { относительно текущего года за счет ребрен- } \\
\text { динга компании, разработки сайта, сокращения штата занятых на } \\
\text { исполнении операций сотрудников на } 50 \% \text { от текущего количества }\end{array}$ \\
\hline $\begin{array}{l}\text { Relevant } \\
\text { (актуальный) }\end{array}$ & $\begin{array}{l}\text { Увеличение собственной прибыли и потенциальных потребителей } \\
\text { организации на } 45 \% \text { относительно текущего года за счет ребрен- } \\
\text { динга компании, разработки сайта, внедрения social media, повы- } \\
\text { шения узнаваемости компании, сокращения штата занятых на ис- } \\
\text { полнении операций сотрудников на } 50 \% \text { от текущего количества на } \\
\text { другие должности }\end{array}$ \\
\hline $\begin{array}{l}\text { Time-bound } \\
\text { (ограниченный } \\
\text { по времени) }\end{array}$ & $\begin{array}{l}\text { К окончанию 2-го квартала следующего года увеличить прибыль } \\
\text { центра на } 45 \% \text { относительно чистой прибыли текущего года за счет } \\
\text { ребрендинга компании, разработки сайта, внедрения social media, } \\
\text { повысить узнаваемость компании, сокращение штата занятых на } \\
\text { исполнении операций сотрудников на } 50 \% \text { от текущего количества } \\
\text { на другие должности }\end{array}$ \\
\hline
\end{tabular}

В условиях сложившейся ситуации можно также рассмотреть альтернативный сценарий для дальнейшего развития медицинского центра. Важно точно взвесить все положительные и отрицательные стороны, которые несет в себе медицин- 
В. В. Безпалов, Д. В. Федюнин, С. А. Автономова. Методы и инструменты разработки фирменного стиля компании в условиях высококонкурентных рынков

ский центр. В связи с этим можно отталкиваться от варианта полного ребрендинга компании, а именно - замена логотипа, работа с социальными сетями компании, создание понятного копирайта, создание визуальных систем для всех маркетинговых инструментов, а также разработка обновленных бренд-основ. Либо же рассмотреть вариант улучшения старого фирменного стиля.

Передача ценности компании напрямую зависит о взаимодействия пациентов и медицинской организации. Благодаря брендбуку медицинского центра цветовая палитра передачи визуальных объектов компании и логотипа бренда будет привлекать потенциальных потребителей и положительно сказываться на их посещении и сайта, а также самого медицинского центра.

С помощью дерева целей была определена стратегия медицинского центра «Авиценна» - формирование конкурентоспособного бренда (рис. 1).

Контурами выбранной стратегии являются:

1. Анализ фирменного стиля конкурентов.

2. Совершенствование фирменного стиля на основе анализа конкурентов и изучения предпочтений потребителей.

3. Комплексное внедрение усовершенствованного фирменного стиля.

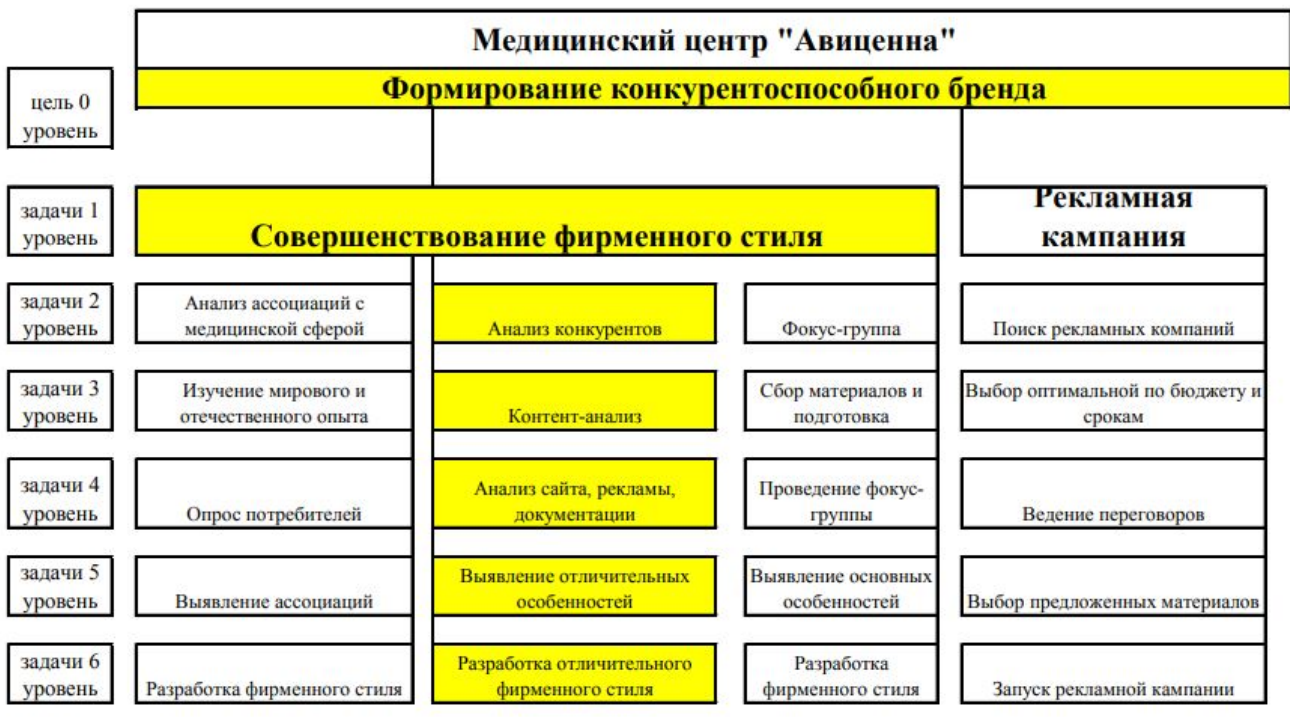

Рис. 1. Дерево целей медицинского центра «Авиценна»

Корпоративная социальная ответственность медицинского центра «Авиценна» развивается в стратегическом преобладающем направлении на базе общих ценностей с другими компаниями, решает социальные проблемы, вызванные действиями корпорации. В связи с этим можно порекомендовать следующие основные мероприятия программы совершенствования фирменного стиля для медицинского центра «Авиценна»:

1. Совершенствование названия: русифицированное название «Авиценна» ассоциируется с медицинской сферой деятельности, но не конкретно со стоматологическими услугами; в данном случае оптимальным является совершенствование название путем добавления компонента-дополнения; например, «дент» (от 
англ. dental «зубной»), который имеет стойкую ассоциативную связь со стоматологической сферой; к тому же по результатам многочисленных исследований отечественных маркетологов буква «д» вызывает яркие радостные эмоции, а в сочетании с не менее «радостной» гласной буквой «а» («Авиценна») - целый ряд положительных оценок; можно предположить, что, таким образом, посредством названия можно будет исключить вероятные страхи клиентов, вызванные спецификой оказываемых стоматологических услуг; в данном случае нецелесообразно использовать слова с буквой «з», которая, как правило, ассоциируется с чем-то страшным и злым.

2. Оптимизация цветового решения: поскольку анализ конкурентов показал, что основным используемым цветом являются оттенки синего (чаще всего светло-голубой), который связан с цветом неба и водных глубин, часто его ассоциации распадаются на ассоциации «голубого» (выбеленного синего) - воздуха, и «синего» - воды; воздух ассоциируется с легкостью, прохладой, одухотворенностью; вода - с тайной, прохладой, тягучестью; в данном случае целесообразным является оставление зеленого как основного фирменного стиля, но подобрать его оттенок с переходом в синий; это позволит, с одной стороны, не выбиваться из общего ряда конкурентов слишком контрастирующим цветом, а с другой - не потеряться на общем голубом фоне; зеленый — цвет спокойствия и гармонии, это цвет жизни, роста, процветания, развития; ассоциации, которые вызывает зеленый, напрямую зависят от его оттенка, например нежный светлый зеленый будет ассоциироваться у большинства потребителей с сочной травой, листьями, природой, этот оттенок вызывает ощущения свежести и радости.

3. Добавление графического изображения зуба: поскольку в логотипе необходимо донести информацию о специфике деятельности организации, чтобы в первые три секунды у клиента выстроилась ассоциативная связь с направлением медицинских услуг (стоматология), то целесообразно визуализировать указанное направление путем графического изображения зуба (поскольку словесное указание направления в логотипе трудно к восприятию).

4. Целостное композиционное оформление логотипа: анализ логотипов конкурентов показал, что, как правило, графическое изображение зуба заключено в какую-либо геометрическую фигуру; в данном случае целесообразно использовать фигуру, напоминающую форму алмаза, который, в свою очередь, будет вызывать ассоциацию с крепостью и здоровьем зубов.

5. Разработка слогана: выигрышным будет использование фирменного слогана, который выразит миссию медицинского центра «Авиценна» и заключит в себе ценностные ориентиры организации (забота о здоровье зубов клиентов, гарантия качества услуг, безболезненность и комплексность процедур).

6. Совершенствование фирменных каналов связи и продвижения: анализ конкурентов показал, что основным каналом связи и продвижения является фирменный сайт, который на протяжении долгого времени у медицинского центра «Авиценна» не работал; в данном случае целесообразно не только создание фирменного сайта, но и формирование и иных современных каналов связи (аккаунт в Инстаграме, страница «ВКонтакте» и иные).

7. Разработка контента для инстаграм-страницы центра: усовершенствование визуального стиля аккаунта, работа с историями, создание видеороликов в формате stop-motion для продвижения рекламы аккаунта. 
В. В. Безпалов, Д. В. Федюнин, С. А. Автономова. Методы и инструменты разработки фирменного стиля компании в условиях высококонкурентных рынков

8. Создание единой униформы сотрудников: отличным вариантом для усовершенствования уникального стиля для компании будет новая линия одежды, расписанная вручную, для того чтобы ввести уникальность в образ сотрудника.

\section{Литература}

1. Гольман И. А. Рекламная деятельность: «Планирование. Технологии. Организация». М.: Гелла-принт, 2002. С. 67.

2. Герасименко В. В., Очковская М. С. Бренд-менеджмент: учеб. пособие. М.: Экономический фак-т МГУ имени М. В. Ломоносова, 2016. 99 с.

3. Основы рекламы: прикладные задачи и методы их решения: учеб. пособие / под ред. Д. П. Фролова, Е. Г. Попковой. М.: КНОРУС, 2016. 194 с.

4. Годин А. М. Брендинг: учеб. пособие. М.: Дашков и Кㅇ, 2016. 184 с.

5. Данилова В. Self-брендинг, или Маркетинг индивидуальности. Ростов н/Д.: Феникс, 2017. 512 с.

6. Домнин В. Н. Брендинг: учебник и практикум для бакалавриата и магистратуры / В.Н. Домнин. Люберцы: Юрайт, 2016. 313 с.

7. Манн И., Турусин Д. Точки контакта. Простые идеи для улучшения вашего маркетинга. Изд. 4. М.: Манн, Иванов и Фербер, 2015. 156 с.

8. Родькин П. Визуальная политика. Фирменный стиль России. М.: Совпадение, 2015. 160 с.

9. Рожков И. Я. Брендинг: учебник. Люберцы: Юрайт, 2016. 331 с.

10. Севостьянов И. О. SEO для клиента. Разработка сайтов. Контекстная реклама. Социальные медиа. Оценка эффективности. М.: Питер, 2016. 672 с.

11. Торшин М. П. Фирменный стиль компании: учеб.-метод. пособие. М.: Издательский центр РГУ нефти и газа (НИУ) имени И. М. Губкина, 2017. 30 с.

12. Ульяновский А. Мифодизайн рекламы. М.; СПб.: Петрополь, 2015. 300 с.

13. Эйри Д. Логотип и фирменный стиль. Руководство дизайнера. Изд. 2. М.: Питер, 2015. 688 с.

Статья поступила в редакцию 27.12.2020; одобрена после рецензирования 28.01.2021; принята к публикации 29.02.2021.

\section{METHODS AND TOOLS FOR DEVELOPING A CORPORATE IDENTITY IN HIGHLY COMPETITIVE MARKETS}

Valery V. Bezpalov

Dr. Sci. (Econ.), A/Prof.

Dmitry V. Fedyunin

Dr. Sci. (Econ.), A/Prof.

Svetlana A. Avtonomova

Cand. Sci. (Sociol.), A/Prof.

Plekhanov Russian University of Economics, 36 Stremyanny Lane, Moscow 117997, Russia

Abstract. After the introduction of anti-sanctions by Russia in relation to some foreign products, the promotion of import substitution in order to implement measures to achieve economic growth of the country becomes relevant. The article discusses measures to implement 
the tasks of a modern marketer, which consists in creating a competitive in-house brand and developing a new recognizable, dominant and life-affirming name. The sanctions against Russia in general and Russian companies in particular can serve as a basis for raising the level of domestic production and attracting consumers to domestic products. For this, it is necessary not only to develop a "domestic quality guarantor", but also to make this product the more recognizable and popular.

Keywords: corporate identity; in-house brand; sanctions; highly competitive markets; trademark; colour scheme and graphic design of corporate documentation. 